\title{
PERCEPCIÓN DE LOS FUTUROS MAESTROS DE PRIMARIA SOBRE EL RIESGO DE INUNDACIÓN. LA GEOGRAFÍA COMO HERRAMIENTA PARA LOGRAR UNA SOCIEDAD MÁS RESILIENTE AL CAMBIO CLIMÁTICO
}

\author{
Álvaro Francisco Morote Seguido ${ }^{l}$ \\ Universidad de Valencia
}

\begin{abstract}
RESUMEN
El riesgo de inundación es el principal peligro natural que afecta a la región mediterránea europea. Este riesgo se ha agravado en las últimas décadas por el incremento de la exposición del ser humano, por ello, tratar estos temas en las aulas de Primaria y la formación de los maestros debe ser una prioridad. Uno de los supuestos resultados de esta investigación es que el futuro profesorado de Primaria tiene la percepción de que este riesgo se ha agravado en los últimos años debido al cambio climático. Los objetivos de este trabajo son: 1) Conocer las experiencias vividas sobre inundaciones de los futuros maestros durante su formación escolar (Primaria); y 2) Analizar cuál es la percepción que tienen sobre la influencia del cambio climático en la aseveración de estos riesgos. Metodológicamente se ha llevado a cabo una investigación de tipo mixta (cuantitativa y cualitativa) con la realización de una encuesta a los futuros maestros de Primaria (caso de estudio de la Facultad de Magisterio, Universidad de Valencia, España). Los resultados indican que la percepción de los/las participantes es que la mayoría de sus centros escolares no se situaban en zonas inundables, y respecto al cambio climático, el 64,52\% cree que está afectando al incremento del riesgo de inundación.
\end{abstract}

Palabras clave: Riesgo; inundación; cambio climático; resiliencia, didáctica.

\section{PERCEPTION OF FUTURE PRIMARY TEACHERS ABOUT FLOOD RISK. GEOGRAPHY AS A TOOL TO ACHIEVE A MOST RESILIENT SOCIETY TO CLIMATE CHANGE}

\section{ABSTRACT}

The risk of flooding is the main natural hazard that affects the European Mediterranean region. This risk has been aggravated in recent decades by the increase in exposure of the human being. Therefore this theme should be a priority in Primary classrooms and the training of teachers. The hypothesis of this research is that the future teachers of Primary school have the perception that the risk of flooding has worsened in recent years due to climate change. The objectives of this work are: 1) To know the experiences of floods of future teachers during their school education (Primary school); and 2) Analyze their perception of the influence of climate change in the assertion of the flood risk. Methodologically, a mixed research (quantitative and qualitative) was carried out with the completion of a questionnaire to future teachers of Primary (Faculty of Teaching, University of Valencia, Spain). The results indicate that the perception of the respondents is that most of their schools were not located in flood zones, and with respect to climate change, in $64.52 \%$ of the cases they believe that it is affecting the increase of flooding.

Key words: Risk; flood; climate change; resilience; instruction.

\footnotetext{
${ }^{1}$ Departamento de Didáctica de las Ciencias Experimentales y Sociales. Universidad de Valencia. Email: alvaro.morote@uv.es
} 


\section{INTRODUCCIÓN}

Los desastres naturales se tratan de eventos que por su magnitud y potencial destructivo ponen en riesgo las vidas humanas y se caracterizan por su compleja predicción y graves consecuencias (IZQUIERDO et al., 2012). En el mundo, los riegos naturales, concretamente los de carácter atmosférico, vienen produciendo una cantidad creciente de pérdidas económicas y humanas (PÉREZ et al., 2015). A escala mundial, según el último informe publicado por el Centre for Research on the Epidemiology of Disasters (CRED), entre 1998-2017, las inundaciones han sido el riesgo natural más frecuente en el mundo (el 43\%) y el que a más personas ha afectado durante este periodo ( 2 billones de hab.), seguidas por las sequías (1,5 billones de hab.). Respecto a las víctimas por inundaciones, en el mundo estas han ascendido a 142.088 (el 11\% por desastres naturales entre 1998-2017), y en relación con los daños económicos, han supuesto unos 656 billones de dólares americanos (el 23\% del total). En Europa, el informe publicado por la Environmental European Agency (2017) indica que entre 2000 y 2014 se produjeron unas 2.000 víctimas mortales y cerca de 8,7 millones de afectados debido a estos fenómenos. También cabe añadir que, respecto al cambio climático, dicho informe pone de manifiesto que las lluvias torrenciales serán más frecuentes e intensas en Europa como también corroboran diferentes informes internacionales (IPCC, 2014; 2018) y nacionales (CEDEX, 2017).

En España, según la información proporcionada por el Ministerio para la Transición Ecológica (2019), las inundaciones constituyen el fenómeno atmosférico que mayores daños materiales ocasionan. En relación con el Consorcio de Compensación de Seguros y el Instituto Geológico y Minero estos daños se estiman en una media de 800 millones de euros anuales. Por ejemplo, cabe destacar que sólo en bienes asegurados, en España, durante el período 1971-2016, el 44,6\% de los expedientes tramitados fueron debidos a daños por este fenómeno. Ello supuso el $62 \%$ del total de las indemnizaciones, las cuales, de media suponen cerca de 130 millones de euros/año. Según OLCINA (2018) en España 2 millones de personas viven en lugares con alto riesgo de inundación y destacando que durante el periodo 1995-2015 fallecieron 526 personas por estos fenómenos. En la Comunidad Valenciana (área de estudio), existe desde 2003 (y actualizado en 2015) el Plan de Acción de Acción Territorial sobre prevención del Riesgo de Inundación en la Comunidad Valenciana (PATRICOVA) (2015). En la memoria de dicho plan se indica que aproximadamente 600.000 habitantes (el 12\% de la población de la región valenciana) residen en zonas con peligro de inundación. Casi un cuarto de millón se ubica en lugares con una peligrosidad menor, pero, cerca de 30.000 tienen su residencia en zonas con un riesgo elevado. Además, como se ha comentado, cabe indicar que estos peligros se incrementarán tanto en intensidad y en frecuencia en el futuro debido a los efectos del cambio climático. Diferentes informes constatan estas afirmaciones y han estimado el aumento de sus consecuencias, especialmente, la pérdida de vidas humanas. Por ejemplo, el quinto informe del Intergovernmental Panel of Climate Change (IPCC) (AR5) (IPCC, 2014), estima que en 2050 los damnificados anuales por inundaciones en Europa pueden ascender a 300.000 y llegarían a 390.000 a partir de los años ochenta del actual siglo XXI.

A la hora de analizar el riesgo, primero cabe explicar su significado. Este concepto en los últimos años ha sido ampliamente estudiado por un colectivo científico interdisciplinar que ha avanzado de forma sustancial hasta consensuar un marco conceptual completo permitiendo comprender las catástrofes naturales como un proceso complejo de relación hombre-medio (MOROTE et al., 2019a; PÉREZ et al., 2016). De manera general se sintetiza en una ecuación en la que el riesgo $(\mathrm{R})=\mathrm{P} \cdot \mathrm{V}$, donde: 1) $\mathrm{P}=\mathrm{El}$ factor físico o peligro; y 2) $\mathrm{V}=\mathrm{El}$ factor humano (vulnerabilidad) (WISNER et al., 2004).

Respecto a la formación del profesorado de Primaria resulta de vital importancia tener en cuenta los conceptos vulnerabilidad espacial, educación ambiental, ciudadana y geográfica, aspectos claves en la Didáctica de las Ciencias Sociales y de la Geografía para lograr un mayor entendimiento del territorio por la sociedad (BENEJAM, 1989; 2011; LÓPEZ et al., 2019; OLLER et al., 2007; SOUTO, 2005; 2007). SOUTO (2007) explica que en los países desarrollados se considera esencial formar a los futuros ciudadanos en aspectos relacionados con la ciencia y que la mejora de la labor docente es probablemente la herramienta más efectiva para mejorar su conocimiento, no sólo en el ámbito científico, sino también en la vida cotidiana ya que 
es parte esencial de la educación geográfica para la ciudadanía. En palabras de TREPAT et al., (2008: 134), "actualmente, en el campo de las Ciencias Sociales, desde una perspectiva de pensamiento crítico, el espacio se considera una variable básica de los hechos sociales y en constante relación dialéctica con la sociedad". En relación con los problemas ambientales, LÓPEZ et al., (2019) ponen de manifiesto que son un reto en todos los sentidos, debido a las intencionalidades sociales, las consideraciones morales y éticas, y especialmente, los intereses económicos. En el ámbito escolar, estos autores indican que es necesario tener clara la finalidad de la enseñanza (con sus objetivos y competencias correspondientes) que debe fundamentarse para preparar a la sociedad a enfrentarse a los retos socio-ambientales de manera constructiva y sostenible, considerando en la ecuación tanto las necesidades naturales como sociales. También cabe tener en cuenta que quizá no baste con el conocimiento que una vez fue útil en el pasado, sino que es necesaria una educación holística (YOUNG, 1993). Es decir, una preparación que capacite para la reflexión crítica y sea consecuente con el cuidado del territorio, donde los problemas pueden ser nuevos y que deben ser afrontados de manera colaborativa por el bien común (LÓPEZ et al., 2019).

La inclusión de los problemas que se pueden denominar como "socio-ambientales" son relevantes en las aulas de Ciencias Sociales, y por lo tanto, requiere un tratamiento necesario en la formación del profesorado. Se trata de una metodología que proviene del ámbito anglosajón (EVANS et al., 1996; FIEN, 1992; OCHOA, 1996). En el caso español, dicho enfoque también se propone a partir de diferentes trabajos y propuestas (ver BENEJAM, 1997; GARCÍA et al., 2000; GARCÍA et al., 2003; PAGÈS et al., 2011; SANTISTEBAN et al., 2014).

Respecto al caso concreto del riesgo de inundación, a escala internacional, diferentes investigaciones en la última década ponen de manifiesto la importancia dedicada al estudio de este fenómeno en las aulas (en todos sus niveles). Por ejemplo, en EE.UU. (LUTZ, 2011; MCWHIRTER et al., 2018), en Europa, en Reino Unido (MCEWEN et al., 2014), Polonia (LECHOWICZ et al., 2014), Eslovenia (BRICELJ, 2013), Rumania (KOVACS et al., 2017), o en Asia (AHMAD et al., 2015). En España, en relación con la Didáctica de la Geografía por un lado, y en relación con el tratamiento de los riesgos de inundación en la formación del profesorado y su enseñanza en las aulas de Educación Primaria, no es habitual encontrar este tipo de trabajos. La mayoría de la producción científica didáctica sobre esta temática destaca en el campo de las Ciencias Experimentales y Naturales (BACH, 2008; DÍEZ, 2015; DÍEZ et al., 2009; FREGENAL, 2009; GARZÓN et al., 2009; MARQUÉS, 2005; VALLS et al., 1990). Desde el campo de la Geografía, estos trabajos son escasos. A modo de ejemplo, cabe citar la investigación de OLLERO (1997) que tiene el objetivo de clarificar conceptos sobre las inundaciones con fines didácticos y para la formación del profesorado y alcanzar una clasificación de las causas y de las grandes consecuencias en el territorio (procesos de crecida e inundación).

En la región valenciana, en los años noventa se llevaron a cabo diferentes unidades didácticas en Educación Primaria bajo el paradigma de la investigación-acción con el objetivo de incidir en la manera de entender las situaciones cotidianas dentro del marco escolar (RAMIRO, 1991; 1996a; 1996b). Estos trabajos buscaban la conexión entre la teoría escolar y la acción práctica social (caso de la "Pantanada de Tous de 1982") y destacando que los objetivos eran especialmente considerar la importancia de la reflexión sobre la acción y no tanto en análisis de la peligrosidad de las riadas. En la región valenciana, salvo estos trabajos de los noventa y algunos publicados recientemente (MOROTE, 2017; MOROTE et al., 2019a), desde una perspectiva de la Didáctica de la Geografía, estos son los escasos trabajos realizados sobre esta temática.

En relación con el cambio climático, en España tampoco es habitual encontrar trabajos desde la Didáctica de la Geografía, a pesar de ser un tema de notable incidencia y actualidad, y ello, teniendo en cuenta que el tema social (ocupación del territorio, concentración de población, percepción sobre el riesgo, etc.), es fundamental para entender el porqué del incremento de este riesgo. Fuera de España destacan investigaciones desde las representaciones sociales del alumnado de Primaria sobre esta temática, por ejemplo, en México (GONZÁLEZ et al., 2014) o en Asia (Singapour) (CHANG, 2012; CHANG et al., 2015; 2016). En España, no obstante, desde la Didáctica de las Ciencias Naturales (al igual que sucedía con las inundaciones) sí que destacan estos trabajos (CALIXTO, 2015; DOMÈNECH, 2014; OUARIACHI et al., 2017; PÉREZ, 2011). La enseñanza del cambio climático supone un reto para los futuros docentes de Primaria debido 
a la responsabilidad de formar a los más jóvenes en la comprensión y posible adaptación a este fenómeno (BOON, 2014; EKLUND, 2018). Esto, por ejemplo, en el ámbito anglosajón se ha sabido trabajar desde hace varias décadas en las aulas de Primaria. Al respecto, destacan diferentes trabajos realizados por la Geographical Association sobre los riesgos de inundación (JONES, 2007; WOODHOUSE, 2007) y el cambio climático (BALLIN, 2007; SPEAR, 2018). Se tratan de propuestas didácticas en las que cobra importancia al factor vulnerabilidad gracias a la formación sobre estos problemas socio-ambientales en el alumnado. En este sentido, según pone de manifiesto un informe publicado por la Agencia Medioambiental Europea existe la necesidad de dar una mayor importancia a este factor ("vulnerabilidad") ya que se trata de un elemento de primer orden para abordar la adaptación al cambio climático y al previsible incremento de episodios de inundación en el territorio europeo hasta final de siglo (EEA, 2017).

Cabe incidir en la importancia de tratar los problemas socio-ambientales desde la Didáctica de la Geografía (LÓPEZ et al., 2019; SOUTO, 2018), además porque así lo establece el currículo para el caso de esta investigación objeto de estudio (Educación Primaria). En la Comunidad Valenciana se establece el actual currículo mediante el Decreto 108/2014 de 4 de julio (independientemente del Real Decreto 126/2014 del Estado que establece las enseñanzas mínimas para la Educación Primaria). En la normativa valenciana, en el Anexo I se recogen los contenidos y criterios de evaluación en el área troncal de Ciencias Sociales donde se inserta la temática de los riesgos de inundación, en concreto, en el Bloque 2 "El mundo en el que vivimos". Estos riesgos se concretan expresamente en el $3^{\text {er }}$ curso de Primaria "consecuencias de las sequías y las inundaciones para la vida de los seres humanos".

Por lo tanto, el interés de esta investigación se debe por diferentes cuestiones: 1) El riesgo de inundación constituye el peligro natural más importante que afecta a España, y especialmente, el área mediterránea; 2) La escasez de investigaciones sobre el proceso de enseñanza-aprendizaje en la formación del profesorado y las representaciones sociales sobre los riesgos de inundación, dentro del ámbito de la Didáctica de la Geografía tanto del área de estudio (levante español) como a nivel nacional; 3) Importancia del factor "educación" ya que se trata de una medida no estructural tradicionalmente desestimada para reducir la vulnerabilidad; 4) Este tema debe tratarse en la Educación Primaria como establece el actual currículo; 5) La importancia de concienciar y enseñar a las cohortes más jóvenes sobre estos fenómenos ya que son ellos/as quienes enseñarán y concienciarán a las futuras generaciones; 6) La región valenciana se ha convertido en una "región-riesgo" tanto por las propias características climáticas como por la ocupación urbana (ocupación y urbanización de zonas inundables); y 7) Según los escenarios futuros de cambio climático, los riesgos de inundación serán cada vez más frecuentes e intensos. Por tanto, se trata de cuestiones de interés para poder lograr una sociedad más resiliente al cambio climático, término que MOROTE et al. (2019b) lo definen como el grado de recuperación y adaptación de una sociedad para hacer frente a una catástrofe natural.

El problema de investigación que se plantea en este trabajo es que el riesgo de inundación es un tema notablemente importante para tratar en las aulas de Primaria, pero debido a la posible escasa formación y desconocimiento que tiene el profesorado sobre esta materia puede resultar algo confuso a la hora de transmitir esta temática a las cohortes más jóvenes. La hipótesis de partida de este trabajo es que el futuro profesorado de Primaria tiene la percepción de que el riesgo de inundación se ha agravado en los últimos años debido al cambio climático (incremento de la peligrosidad), y por tanto, no contemplando el factor vulnerabilidad (incremento de la urbanización y ocupación de zonas inundables, percepción de riesgo 0, etc.). Los objetivos de esta investigación son: 1) Conocer las experiencias vividas sobre inundaciones de los futuros maestros durante su formación escolar (Primaria); y 2) Analizar cuál es la percepción que tienen éstos sobre la influencia del cambio climático en la aseveración del riesgo de inundación. Tras la Introducción donde se plantea el interés y el problema de investigación, se presenta la Metodología seguida, la descripción de los resultados obtenidos, la Discusión, y finalmente, las Conclusiones.

\section{MÉTODO}

\subsection{DISEÑO DE LA INVESTIGACIÓN}


En este trabajo se presenta un estudio descriptivo y exploratorio de tipo mixto (no experimental), y respecto al tipo de investigación didáctica, se caracteriza por tener un enfoque socio-crítico. También cabe indicar que adopta un diseño transversal ya que la información obtenida de los/las participantes se recoge en un momento puntual (curso 2018-19) y a modo de estudio de caso (un grupo determinado de alumnos/as de la Facultad de Magisterio de la Universidad de Valencia, España).

\subsection{CONTEXTO Y PARTICIPANTES}

En relación con el contexto y los/las participantes, el procedimiento de selección de éstos ha sido un muestreo no probabilístico (muestreo disponible o de conveniencia). Se han seleccionado dos grupos del $4^{\circ}$ curso del Grado en Maestro en Educación Primaria de la Facultad de Magisterio de la Universidad de Valencia que cursan la asignatura de "Didáctica de las Ciencias Sociales. Aspectos Aplicados" (código 33651; curso 2018-19). En relación con los dos grupos seleccionados no se encontraron diferencias significativas. La única diferencia es que sólo se tratan de grupos con el interés de cursar distintas menciones (Especialista en Artes y Humanidades y Especialista en Educación Física). Respecto a la representatividad de la muestra, teniendo en cuenta el total de discentes matriculados en el Grado en Maestro de Primaria durante el curso 2018-19, la cifra de la población asciende a 2.126 (Universidad de Valencia, 2019). Por tanto, con un nivel de confianza del $90 \%$ y un margen de error del 10\%, la muestra representativa debería ser de 66 participantes. Si se tiene en cuenta el número de matriculados de los dos grupos escogidos (un total de 86), un nivel de confianza del $95 \%$ y un margen de error del $5 \%$, para obtener una muestra representativa esta debería ser de 71 . Finalmente, la cifra total de encuestados/as ascendió a 74 logrando por tanto un número de participantes representativo.

Por las propias características del alumnado de Magisterio cabe destacar que el género de la mayoría de éstos/as es femenino. Para esta investigación el 69,77\% fueron mujeres. Los datos facilitados por la Universidad de Valencia (2019) para el caso de la Facultad de Magisterio (curso 2017-18) indican que el 69,6\% de los matriculados/as son mujeres. Respecto a la edad se trata de una muestra que mayoritariamente se encuentra en el rango de edad entre los 21-25 años (88,37\%) y el 11,62\% restante entre los 26-40 años de edad. También es importante destacar el tipo de acceso a los estudios universitarios del Grado en Maestro en Educación Primaria. El 75,58\% accedió mediante la realización de las Pruebas de Acceso a la Universidad (PAU), el 16\% mediante un Ciclo Formativo, el 4,65\% a partir de traslado desde otras titulaciones y el 2,32\% a partir de las pruebas para personas mayores de 25 años.

\subsection{INSTRUMENTO DE ANÁLISIS}

Para el proceso de recogida de datos, teniendo en cuenta el instrumento, este ha consistido en la realización de un cuestionario que ha permitido obtener la información necesaria para responder a los objetivos propuestos. Se trata de un instrumento que, para este caso, permite la obtención de datos en ausencia de manipulación o intervención por parte del experimentador. Por tanto, como explican ALAMINOS et al., (2006) permite utilizar procedimientos de observación o medidas consistentes y estandarizadas para todos los sujetos, de forma que quede garantizada la comparabilidad de los datos.

El cuestionario se dividía en 7 partes y un total de 16 ítems (ver Tabla 1). Para este trabajo (según los objetivos propuestos) se han utilizado los resultados obtenidos de: Parte $1^{\text {a }}$ "Características socio-culturales y educativas"; Parte $5^{\mathrm{a}}$ "Episodios de inundación en el centro escolar. El camino de casa al colegio"; y Parte $6^{\text {a }}$ "La incidencia del cambio climático en los riesgos de inundación". Al tratarse de un estudio exploratorio mixto, el cuestionario estaba compuesto tanto por preguntas de respuestas cerradas (escala Likert) y abiertas. Respecto a la escala Likert, MORALES (1981) explica que permite la utilización de ítems que no están directamente relacionados con la actitud que se pretende medir. En este sentido, se da la posibilidad de establecer mediciones de carácter indirecto que, en otros métodos, como el de Thurstone, se halla notablemente limitado. Su construcción es sencilla ya que se puede realizar con un trabajo menor y de modo más rápido que en otras escalas y el número de ítems que se 
necesitan para su confección suele ser menor que en otras. Su fiabilidad suele ser muy elevada, permitiendo, además, el establecimiento de graduaciones o intensidad de respuesta. Las posibles respuestas de cada ítem permiten un mayor grado de información sobre la actitud estudiada. Respecto a las respuestas abiertas, diferentes autores han resaltado la importancia de estas por considerarse adecuado en el ámbito de las Ciencias Sociales (TASHAKKORI et al., 2003).

TABLA 1

Partes 1,5 y 6 del cuestionario

Parte 1. Características socio-culturales y educativas
Ítem 1. Sexo
Ítem 2. Edad
Ítem 3. Forma de acceso al Grado en Maestro de Educación Primaria
Ítem 4. Lugar de nacimiento
Ítem 5. Localidad del centro escolar durante la que se estudió el ciclo de Primaria

Parte 5. Episodios de inundación en el centro escolar. El camino de casa al colegio

Ítem 11. Durante tu etapa escolar (Primaria), ¿Tu colegio estaba situado en zona inundable o en zona de riesgo de inundación? (por ejemplo, en ramblas, marjales, etc.).

Ítem 12. ¿El camino de tu casa al colegio transcurría por zonas con peligro de inundación?

Ítem 13. ¿Viviste algún episodio grave de inundación en tu colegio? ¿Puedes describir brevemente qué ocurrió y cómo se actuó?

Parte 6. La incidencia del cambio climático en los riesgos de inundación

Ítem 14. ¿Crees que ahora la forma de llover ha cambiado en comparación cuando ibas al colegio?

Ítem 15. ¿Crees que el cambio climático está influyendo en la aseveración de los riesgos de inundación?

$$
\text { Elaboración propia. }
$$

En relación con las respuestas de estas tres partes del cuestionario cabe indicar que todos/as los/las participantes contestaron. Para el caso de la primera parte tenían que contestar su estado (sexo, edad, forma de acceso al Grado, lugar de nacimiento y municipio del centro escolar donde cursaron los estudios de Primaria). Respecto a la quinta parte (ítems 11, 12 y 13), las respuestas son abiertas. En caso de ser afirmativas, los/las participantes debían explicar brevemente la situación de su centro escolar y los episodios de inundación vividos en él o durante el trayecto desde su hogar o viceversa. Finalmente, la parte sexta del cuestionario se compone de los ítems 14 y 15 siendo respuestas cerradas: Ítem 14 (7 posibilidades) (Llueve más pero más intensamente; llueve más; llueve igual pero más intensamente; Llueve igual; Llueve menos pero más intensamente; Llueve menos; Ns/Nc); Ítem 15 (5 posibilidades) (1: Sí, mucho; 2: Sí; 3: Indiferente; 4: Poco; y 5: No, de ninguna manera). En este ítem, aparte de que cada respuesta se vincula con una puntuación numérica, también se contemplaba la respuesta de "Ns/Nc" (opción de marcar una casilla), y además se dejaba un apartado para que los/las participantes pudieran comentar alguna experiencia u opinión.

Respecto a la consistencia interna del cuestionario y con la intención de poder extraer conclusiones válidas y concluyentes se ha utilizado el programa estadístico SPSS (versión 23). Los datos arrojan un Coeficiente de Fiabilidad de Alfa de Cronbach de $\alpha=0,931$ que indica el valor elevado obtenido de los resultados (COHEN et al., 2002). Otro índice a mencionar para la validez de los ítems y la estructura del instrumento utilizado es el valor de Chi-Cuadrado de Pearson. Éste ofrece un resultado de p-valor $<1=$ Sig. 0,001 (COHEN et al., 2002). Por tanto, estos valores indican la alta correlación de las preguntas planteadas y de la validez del cuestionario confeccionado. Este instrumento también fue validado por tres docentes adscritos a los departamentos de Didáctica de las Ciencias Experimentales y Sociales de la Universidad de Valencia y Análisis Geográfico Regional y Geografía Física de la Universidad de Alicante. El cuestionario se administró en una sesión intermedia (primer cuatrimestre) durante la última semana del mes de noviembre y con un tiempo de respuesta de 30 minutos. Finalmente, cabe destacar que todo este procedimiento se llevó a cabo preservando el anonimato, elaborando listados por número de alumnado y garantizando por escrito el tratamiento confidencial de la información.

\section{RESULTADOS}




\subsection{LUGAR DE NACIMIENTO Y LOCALIZACIÓN GEOGRÁFICA DEL CENTRO ESCOLAR}

En relación con las preguntas vinculadas con las características socio-culturales, en este apartado se han destacado las referentes al lugar de nacimiento y localización geográfica (municipio) donde se ubican los centros escolares en el que los/las encuestados/as cursaron sus estudios de Primaria. Respecto a la primera cuestión, la mayoría de los/las participantes han nacido en la provincia de Valencia (el 89,52\%), siendo de la capital el $29,06 \%$ y el $60,46 \%$ del resto de la provincia (Tabla 2). Por tanto, a priori, se trata de una población "autóctona" que ha nacido y reside en un territorio donde el riesgo de inundación es el principal peligro natural y que es característico del clima mediterráneo (episodios de lluvias intensas).

TABLA 2

Lugar de nacimiento de los/las participantes

\begin{tabular}{|l|r|r|}
\hline & \multicolumn{1}{|c|}{$\mathbf{n}^{\mathbf{0}}$} & \multicolumn{1}{c|}{$\%$} \\
\hline Provincia de Valencia (excepto ciudad de Valencia) & 52 & 60,46 \\
\hline Ciudad de Valencia & 25 & 29,06 \\
\hline Com. Valenciana (otras provincias) & 5 & 5,81 \\
\hline España (excepto Com. Val.) & 3 & 3,48 \\
\hline Otro país & 1 & 1,16 \\
\hline
\end{tabular}

Fuente: Resultados de la encuesta. Elaboración propia.

En relación con la localización geográfica del centro escolar donde los/las encuestados/as cursaron Primaria cabe destacar que los datos ponen de manifiesto una correlación con el lugar de nacimiento. La mayoría de los centros se ubican en la provincia de Valencia (el 90,5\%), siendo minoritarios aquellos ubicados en las provincias de Alicante (el 5,04\%) y Castellón (el 4,05\%) (Figura 1). Respecto a la provincia de Valencia, los datos indican la notable influencia que ejerce el área metropolitana de Valencia (capital de provincia con 1.559 .908 habitantes; el 61,62\% del total provincial) (Ayuntamiento de Valencia, 2019). También, sumado a la concentración de población en esta área, cabe añadir el mejor acceso y facilidad de comunicaciones de los/las estudiantes para acceder a la universidad (Facultad de Magisterio de la Universidad de Valencia, Campus de Tarongers), que además, ha influido en que la mayoría sean de esta área metropolitana. Teniendo en cuenta esta región, la antigua comarca de la Huerta de Valencia, desagregada desde 1989 entre Huerta Norte, Huerta Oeste, Huerta Sur y Ciudad de Valencia (la única ciudad-comarca de la Comunidad Valenciana), se concentra el 63,5\% de los centros de Primaria de los/las encuestados/as: Ciudad de Valencia (32,43\%), Huerta Oeste (16,21\%), Huerta Norte $(12,16 \%)$ y Huerta Sur $(2,7 \%)$. En segundo lugar, destacan algunas comarcas como las dos Riberas (Alta y Baixa) y La Costera que aglutinan el 6,75\% de los centros respectivamente y el Camp de Morvedre (4,05\%).

FIGURA 1

Localización de los principales centros escolares donde los/las participantes realizaron sus estudios de Primaria 


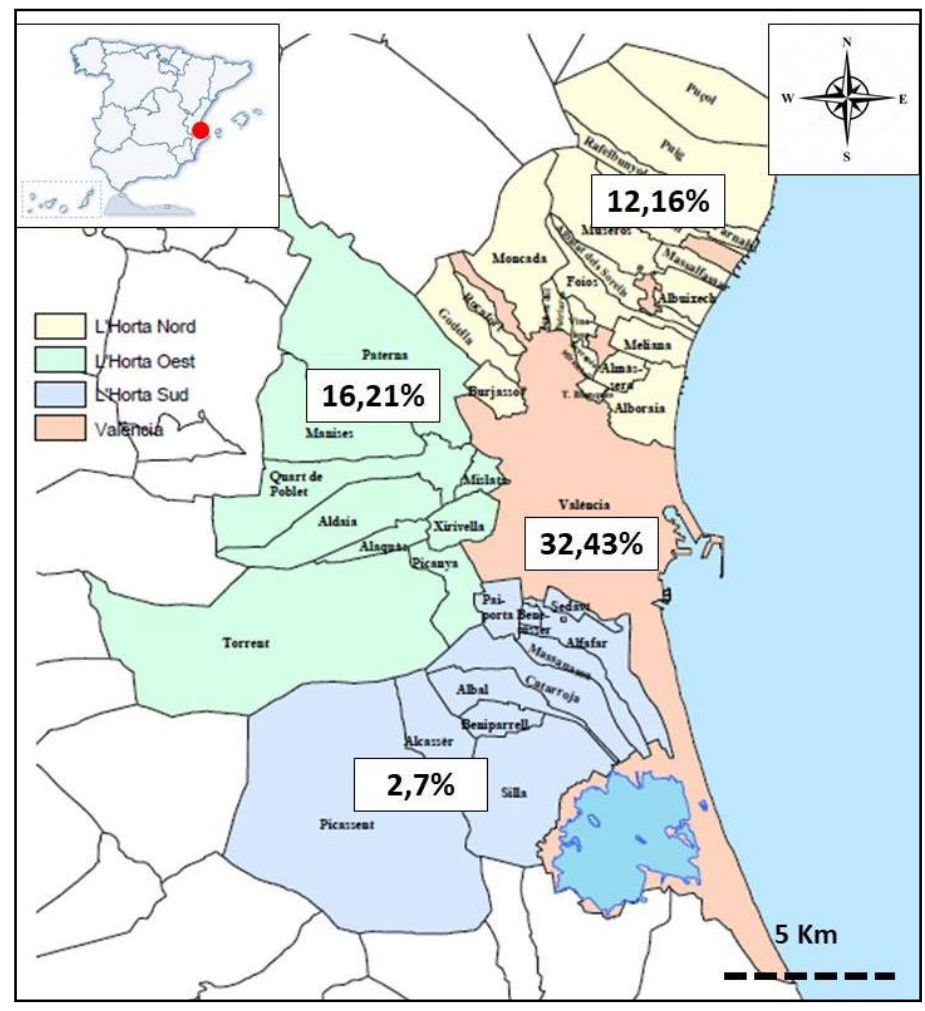

Elaboración propia.

\subsection{VIVENCIAS SOBRE EL RIESGO DE INUNDACIÓN. "EL CAMINO DE CASA AL COLEGIO"}

La quinta parte del cuestionario tiene el objetivo de conocer: 1) La situación de riesgo del centro escolar donde los/as futuros/as maestros/as realizaron sus estudios de Primaria. Esta pregunta tiene la finalidad de comprobar si son capaces de identificar si el centro se encontraba en una zona inundable; 2) Analizar si los/las participantes sabían si el trayecto de su casa al colegio (y viceversa) transcurría por alguna zona con peligro de inundación; y 3) Conocer las experiencias vividas durante episodios de inundación en el centro escolar y cómo se procedió a actuar (si fuese el caso). Respecto a la primera cuestión (ítem 11), cabe destacar que las respuestas mayoritarias de los/las participantes fue que el $79,72 \%$ de los centros no se situaban en zonas inundables. El 18,92\% afirmó que sí se localizaba en zonas con peligro y el resto (el $1,35 \%$ ) contestó que no sabía acerca de este peligro. En relación con los que afirmaron positivamente destacan diferentes opiniones y situaciones descritas. Por ejemplo, "Sí, un día que llovió mucho no pudimos salir del colegio", "Sí, en una zona de marjal", "Sí, una parte del colegio estaba en una rambla", "Sí, el colegio se sitúa cerca de un río seco" (Tabla 3). 
Respuestas afirmativas de los/las participantes según comarcas del ítem 11 "Durante tu etapa escolar (Primaria), ¿Tu colegio estaba situado en zona inundable o en zona de riesgo de inundación? (por ejemplo, en ramblas, marjales, etc.)"

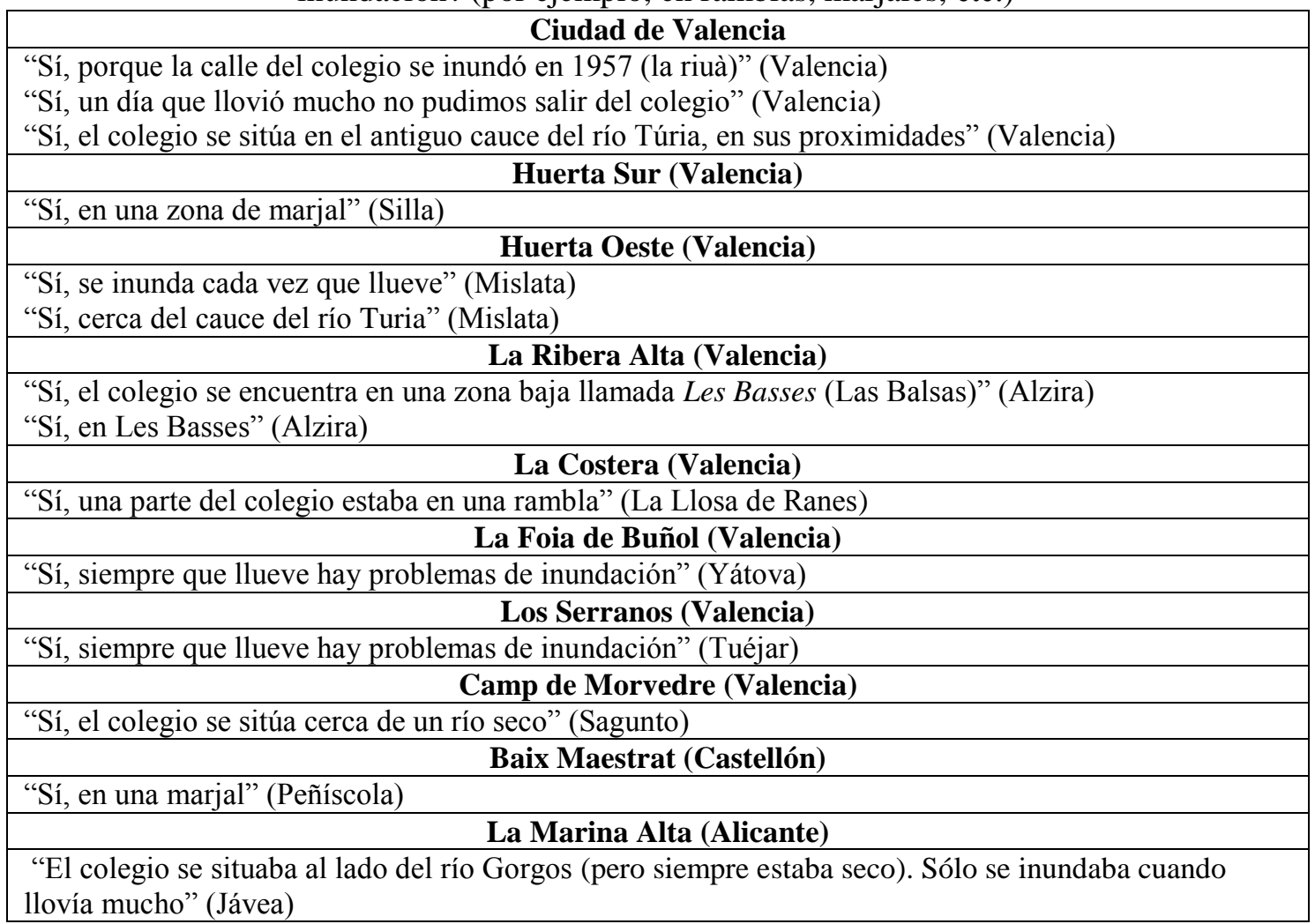

Fuente: Resultados de la encuesta. Elaboración propia.

TABLA 4

Respuestas afirmativas de los/las participantes según comarcas del ítem 12. ¿El camino de tu casa al colegio transcurría por zonas con peligro de inundación?

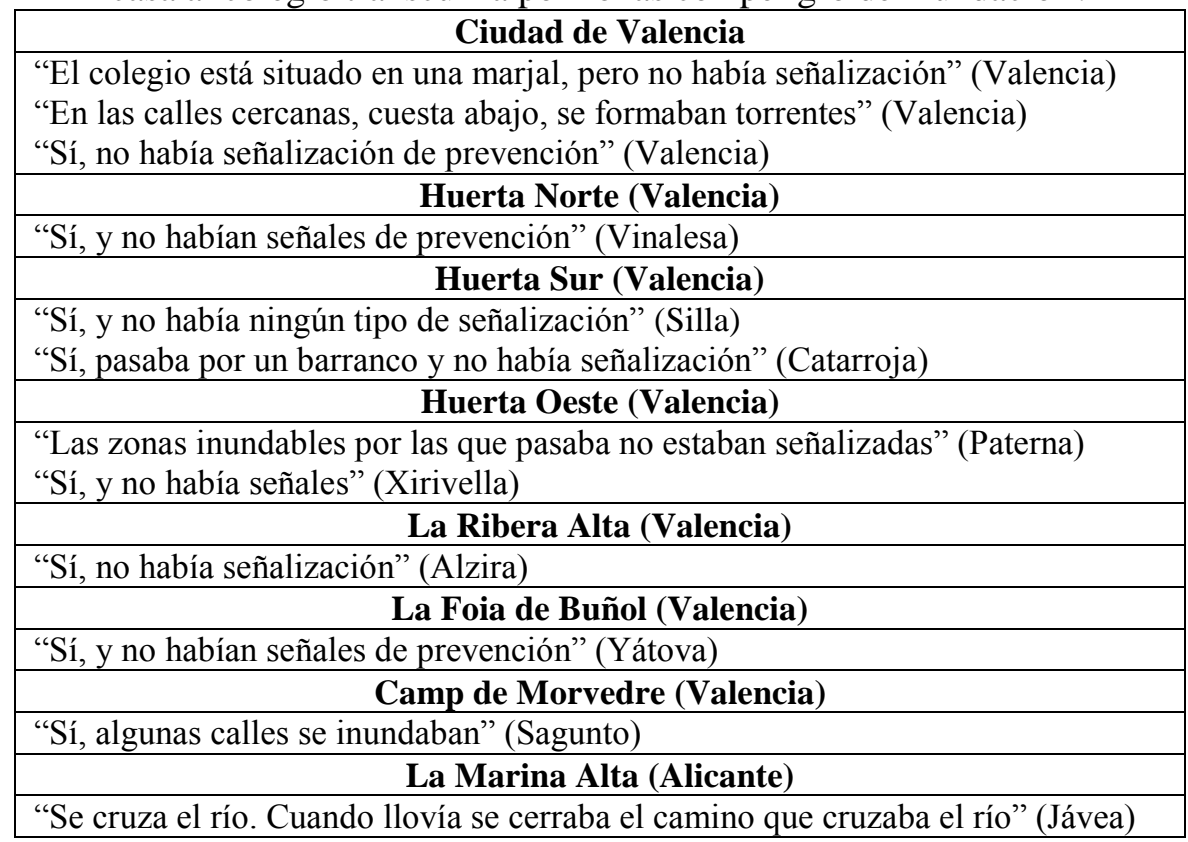

Fuente: Resultados de la encuesta. Elaboración propia.

Respecto al ítem 12 del cuestionario “ ¿El camino de tu casa al colegio transcurría por zonas con peligro de inundación?, la mayoría ha contestado negativamente (el 79,72\%), mientras que el 16,21\% afirmó que para el trayecto de casa al centro y viceversa se transcurría por zonas con 
peligro. El 4,05\% restante contestó que no sabía sobre esta situación. Algunos de los comentarios de los/las participantes que respondieron afirmativamente fueron "El colegio está situado en una marjal, pero no había señalización", "Sí, pasaba por un barranco y no había señalización", "Se cruza el río. Cuando llovía se cerraba el camino que cruzaba el río" (Tabla 4).

La última pregunta tiene el objetivo de comprobar y analizar la experiencia vivida por los/as futuros/as maestros/as durante los episodios de inundación sufridos en su etapa escolar. La mayoría, el 79,72\% ha afirmado que no vivió ninguna experiencia de riesgo mientras estaba en el colegio. En la Tabla 5 se recogen los comentarios de los que sí vivieron alguno de estos episodios (el 20,27\%): "Sí, una vez, el agua llegaba más arriba de la cintura, se sacó el agua con bombas. Se inundó todo el colegio", "Sí, la mala construcción del centro hizo que el agua de la calle entrará dentro", "Sí, por ejemplo, la rambla del pueblo se desbordó", "Cuando llovía mucho nos metían en el gimnasio que estaba en el sótano, pero había goteras y se hacían charcos. Teníamos que sacar el agua con cubos". También cabe indicar que de los que contestaron negativamente, el 15,09\% destacó que su centro tenía problemas de goteras durante episodios de lluvias intensas.

TABLA 5

Respuestas afirmativas de los/las participantes según comarcas del ítem 13 ¿Viviste algún episodio grave de inundación en tu colegio? ¿Puedes describir brevemente qué ocurrió y cómo se actuó?

\begin{tabular}{|c|}
\hline $\begin{array}{r}\text { Ciudad de Valencia } \\
\end{array}$ \\
\hline $\begin{array}{l}\text { "Sí, se cancelaron las clases por fuertes lluvias" (Valencia) } \\
\text { "Sí, una vez, el agua llegaba más arriba de la cintura, se sacó el agua con bombas. Se inundó todo el } \\
\text { colegio" (Valencia) } \\
\text { "Sí, la mala construcción del centro hizo que el agua de la calle entrará dentro" (Valencia) }\end{array}$ \\
\hline Huerta Norte (Valencia) \\
\hline "Sí, una vez suspendieron las clases porque llovió mucho y hubo goteras" (Burjassot) \\
\hline Huerta Sur (Valencia) \\
\hline "Sí, por ejemplo, la rambla del pueblo se desbordó” (Silla) \\
\hline Huerta Oeste (Valencia) \\
\hline $\begin{array}{l}\text { "Cuando llovía mucho nos metían en el gimnasio que estaba en el sótano, pero había goteras y se hacían } \\
\text { charcos. Teníamos que sacar el agua con cubos" (Mislata). } \\
\text { "Sí, cerraron alguna vez el colegio porque había entrado agua" (Mislata) } \\
\text { "Sí, se inundó el gimnasio una vez y se cerró el colegio" (Mislata) }\end{array}$ \\
\hline La Ribera Alta (Valencia) \\
\hline "Sí, cerraron alguna vez el colegio por goteras y porque se habían inundado las áreas cerc \\
\hline Camp de Morvedre (Valencia) \\
\hline $\begin{array}{l}\text { "Sí, se inundaban los patios y el gimnasio por las fuertes lluvias" (Sagunto) } \\
\text { "Sí, una vez soltaron la presa y no pudimos ir a clase durante } 2 \text { días" (Sagunto) }\end{array}$ \\
\hline La Marina Alta (Alicante) \\
\hline $\begin{array}{l}\text { "Sí, en } 2007 \text { (gota fría de octubre), Jávea se inundó porque se desbordó el río Gorgos. Las clases se } \\
\text { cancelaron" (Jávea) } \\
\text { "Sí, pero porque el colegio se inundaba por las goteras y tenían que cerrar el colegio" (Gata de Gorgos) }\end{array}$ \\
\hline
\end{tabular}
Fuente: Resultados de la encuesta. Elaboración propia.

\subsection{LA INCIDENCIA DEL CAMBIO CLIMÁTICO EN LOS RIESGOS DE INUNDACIÓN}

La sexta parte del cuestionario tiene la finalidad de conocer la percepción que tienen los futuros maestros sobre el cambio climático y su influencia en los riesgos de inundación (Ítem 14. ¿Crees que ahora la forma de llover ha cambiado en comparación cuando ibas al colegio?; Ítem 15. ¿Crees que el cambio climático está influyendo en el riesgo de inundación?). En el ítem 14 se han diferenciado dos tipos de respuestas, aquellas que se relacionan con la cantidad de precipitación y la forma de llover (intensidad). Respecto a los resultados de la primera destacan cuatro percepciones diferentes: 1) La creencia de que está lloviendo menos (36,5\%); 2) Percepción de que llueve igual (36,49\%); 3) Aquellos/as que piensan que llueve más (21,62\%); y 4) Los/las que no saben realmente si ha habido un cambio (el 5,40\%). En relación si ha habido algún cambio en 
la forma de llover también se encuentran diferencias. Por ejemplo, de los que han contestado que llueve igual, destacan dos grupos:

1. Los/las que afirman que ahora precipita la misma cantidad pero lo hace más intensamente (el 19,92\%)

2. Los/las que piensan que llueve igual pero sin diferencias en la intensidad $(17,57 \%)$.

Respecto a los/las que contestaron que ahora llueve menos se diferencian también dos grupos:

1. Los/las que piensan que ahora llueve menos pero con una mayor intensidad (el $22,98 \%)$.

2. Los/las que perciben que llueve menos pero sin diferencias en la intensidad (el $13,52 \%)$.

En relación con el grupo de encuestados/as que explican que ahora llueve más también se distinguen dos grupos:

1. Los/las que piensan que ahora llueve más pero sin ninguna diferencia en la intensidad $(13,52 \%)$.

2. Los/las que creen que ahora llueve en mayor cantidad y de una forma más intensa (el $8,10 \%)$.

Por lo tanto, los resultados ponen de manifiesto una disparidad notable de opiniones en las que, por número de respuestas, destacan: 1) Discentes que perciben que ahora llueve menos y con una mayor intensidad $(22,98 \%)$; 2) Llueve igual pero más intensamente $(18,92 \%)$; y 3 ) Llueve igual pero sin diferencias en la forma de llover (17,57\%) (Figura 2).

FIGURA 2

Ítem 14. ¿Crees que ahora la forma de llover ha cambiado en comparación cuando ibas al colegio?

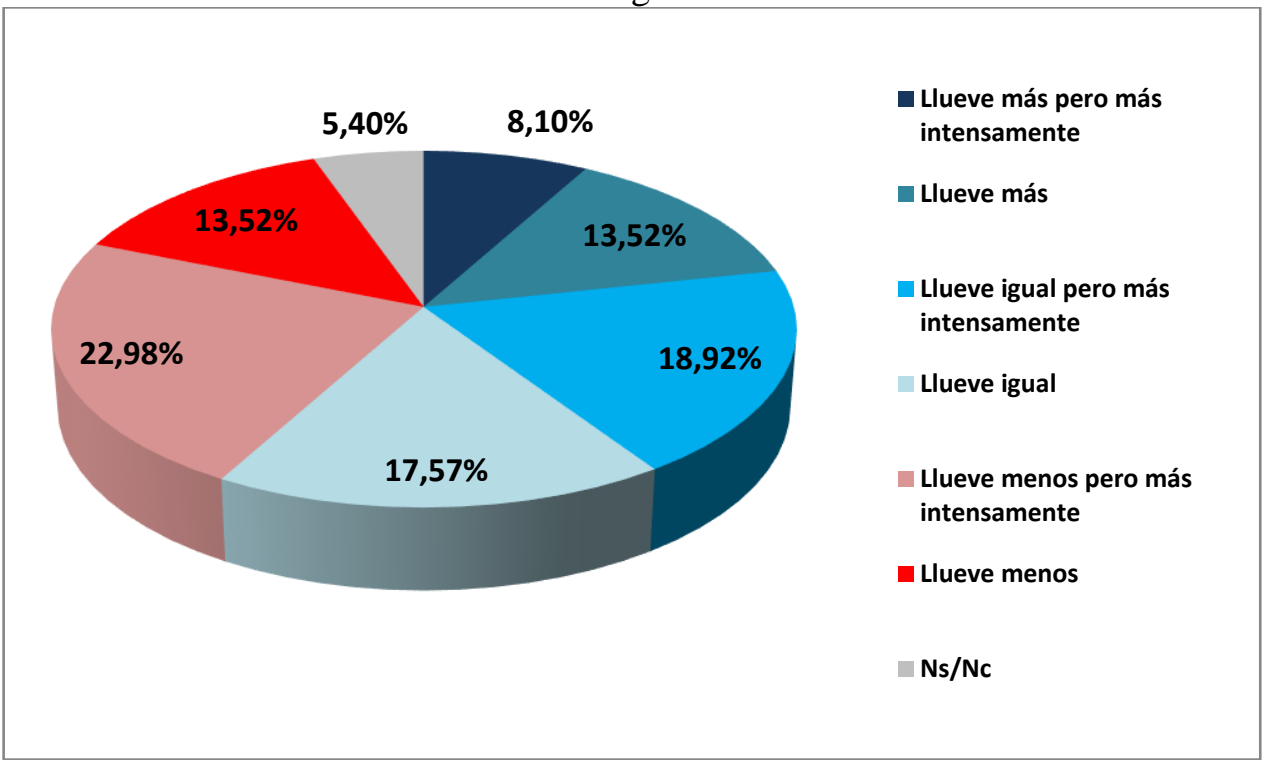

Fuente: Resultados de la encuesta. Elaboración propia.

En la segunda y última pregunta de esta parte (ítem 15), los resultados evidencian una percepción más clara que la pregunta anterior. La mayoría, el 64,52\% cree el cambio climático tiene una incidencia directa en la aseveración de estos riesgos (Figura 3). Especialmente destacan los/las que contestaron que el cambio climático está influenciando "mucho" (el 37,84\%), y en segundo lugar, los/las que "sí" creen que influye (el 26,68\%). También cabe mencionar dos grupos de participantes que opinan que el cambio climático está influenciando "poco" en los riesgos de inundación y "no, de ninguna manera". Entre estos dos grupos de opiniones se aglutina el 31,08\% de las respuestas. Resulta interesante analizar los comentarios que describieron estos últimos participantes que justifican los problemas de inundación por: 1) La deficiente planificación urbana y ocupación de zonas inundables ("Edificar casas en zonas inundables no es correcto", "muchas casas están construidas en ramblas, cerca de barrancos", "Las calles y ciudades no están preparadas para la lluvia", "Carreteras mal situadas", "Construcciones pegadas 
al barranco", "Casas al lado de un barranco", "Urbanización en ramblas, poca limpieza del alcantarillado, pasos a nivel", "Edificios muy cerca de los ríos, campos de cultivo dentro del mismo río"); y 2) Cuestiones relativas a la falta de limpieza de cauces ("Utilizar el barranco como vertedero", "Poca limpieza de los montes, barrancos, etc.").

FIGURA 3

Ítem 15. ¿Crees que el cambio climático está influyendo en la aseveración de los riesgos de inundación?

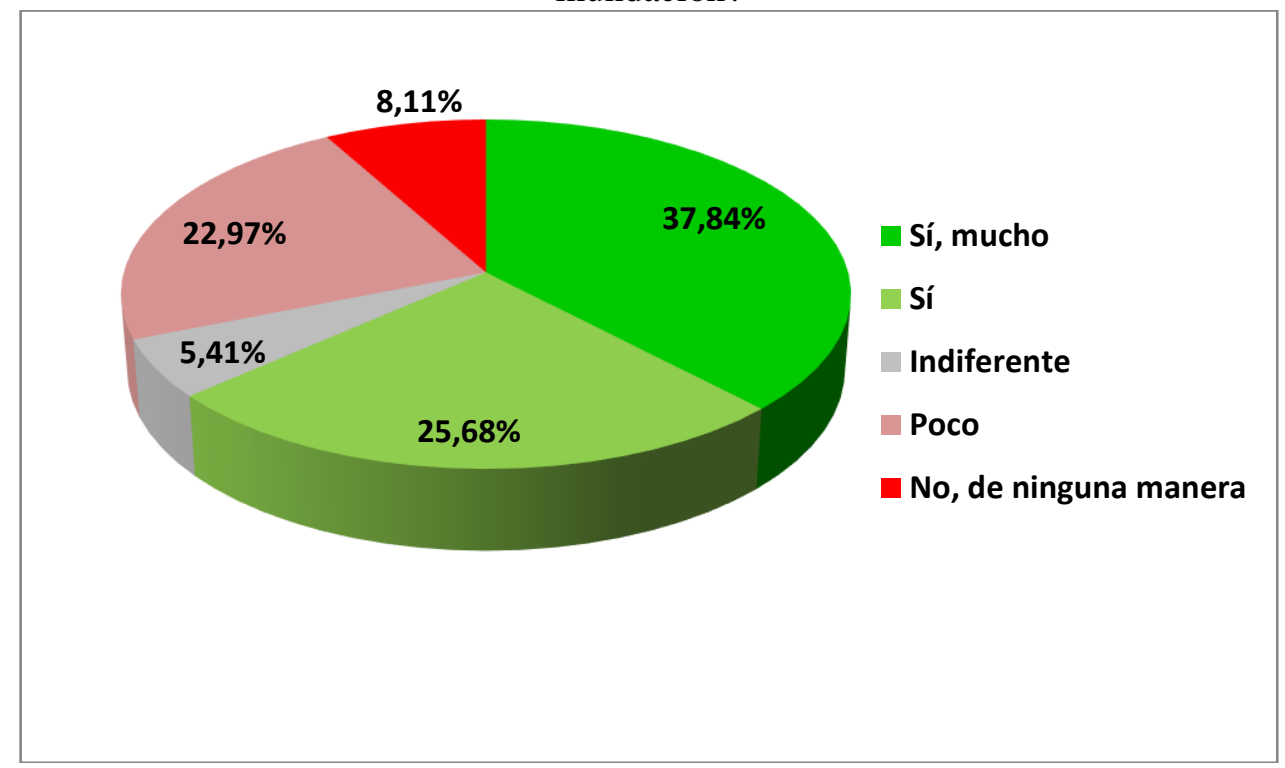

Fuente: Resultados de la encuesta. Elaboración propia.

\section{DISCUSIÓN}

Tras el análisis de los resultados obtenidos para el caso de la muestra escogida (Facultad de Magisterio; Universidad de Valencia), se puede afirmar que se cumple la hipótesis de partida "el futuro profesorado de Primaria tiene la percepción de que el riesgo de inundación se ha agravado en los últimos años debido al cambio climático (incremento de la peligrosidad), y por tanto, no contemplando el factor vulnerabilidad".

En primer lugar, cabe destacar que los resultados obtenidos se pueden generalizar al área de estudio de la provincia de Valencia, y más concretamente al Área Metropolitana de la capital (la antigua comarca de la "Huerta de Valencia") ya que es en esta zona donde reside la mayoría de los/las encuestados/as. También cabe poner de manifiesto que la información recopilada trata sobre las experiencias y percepción. Por tanto, también dependerá del conocimiento del territorio y la memoria climática (no hay que olvidar que algunas cuestiones hacen referencia a un marco temporal de hace 10-15 años), teniendo en cuenta que los tres ciclos de Primaria comprenden un rango de edad entre los 6-12 años, por tanto, principios del s. XXI.

Respecto a la pregunta sobre la ubicación del colegio en zona inundable, la mayoría de los/las participantes contestó que no se encontraba en estos espacios. También los resultados obtenidos indican que la mayoría recuerda que no transitaba por zonas con peligro de inundación durante el trayecto de casa a la escuela. Ello no implica que haya un grupo de participantes, caso de la primera cuestión mencionada (el 18,92\%) y el 16,21\% (caso de la segunda) que sí han percibido estos riesgos. Además, cabe destacar que algunas opiniones mostradas relacionadas con los problemas de inundación se asocian a la existencia de goteras en el centro y a la no señalización de zonas inundables en el camino de casa al colegio. Con los resultados de esta parte del cuestionario se evidencia que hay un pequeño grupo de participantes que han percibido y vivido estos fenómenos durante su etapa escolar (o por lo menos lo recuerdan).

En relación con los resultados obtenidos sobre la influencia de cambio climático en las precipitaciones cabe poner de manifiesto que según la percepción de los/las discentes, las 
principales respuestas se relacionan con que ahora llueve más intensamente. El 22,08\% piensa que llueve menos pero más intensamente y el $18,98 \%$ cree que ahora llueve igual, pero de una forma más intensa. Tan sólo estos dos grupos de respuestas aglutinan el 41,9\% del total. El ítem sobre la influencia del cambio climático en la aseveración de los riesgos de inundación evidencia que hay una mayoría (el 64,52\%) que cree que sí que está ejerciendo una incidencia. No obstante, el 31,08\% piensa lo contrario. En este caso los discentes han opinado que el incremento del riesgo se debe más por el aumento de la vulnerabilidad (deficiente ocupación del territorio por la construcción en zonas inundables, no señalización de zonas con peligro, etc.), que por la peligrosidad (incremento de la intensidad de las lluvias). Se podría pensar que esta percepción se pueda deber a que sean estos/as encuestados/as los que han contestado que sus colegios se encuentran en zonas inundables (experiencias de inundación vividas durante la etapa escolar). Sin embargo, a la hora de relacionar estas dos variables los resultados no evidencian una diferencia significativa con aquellos que contestaron que su colegio no se encontraba en zona de riesgo (Figura 4). Para el caso de los primeros el valor medio de la puntuación sobre la influencia del cambio climático en la aseveración del riesgo es 2,46, mientras que, para el segundo, 2,40. Por tanto, una valoración entre "2-Sí, hay influencia" y "3-Indiferente".

FIGURA 4

Opinión sobre la influencia del cambio climático de los/las participantes que vivieron algún episodio de inundación en su colegio

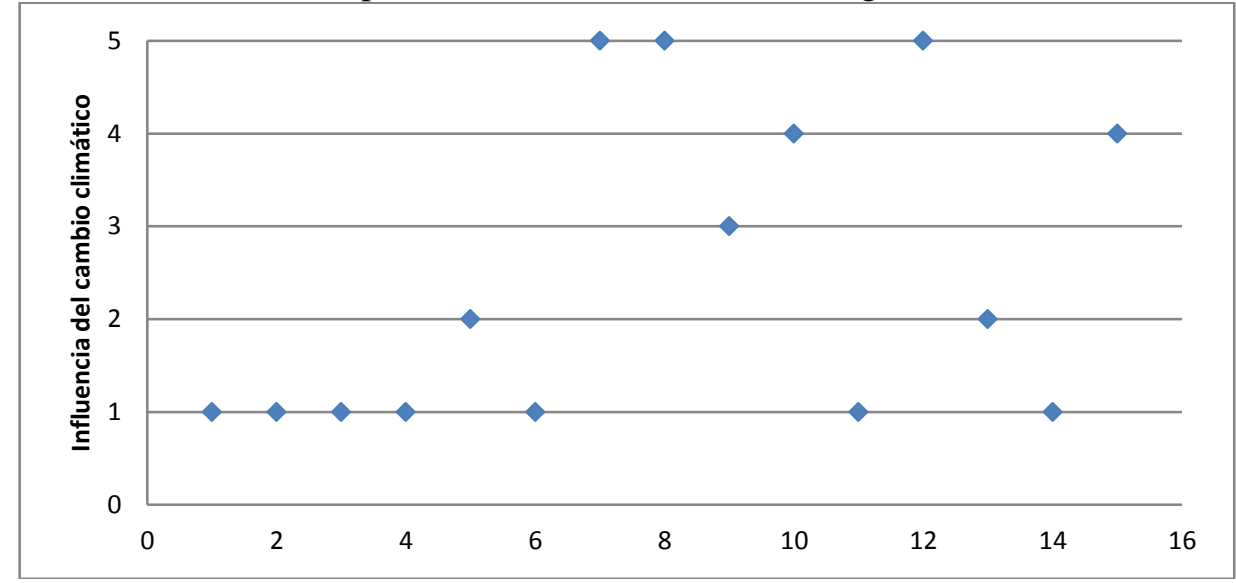

Fuente: Resultados de la encuesta. Nota: En el eje X se han representado los/las participantes que vivieron algún episodio de inundación en su colegio y en el eje Y la importancia de la influencia del cambio climático en la aseveración del riesgo de inundación (1-Sí, muy importante; 2- Sí; 3- Indiferente; 4- Poca; 5- No, de ninguna manera.).

Estas opiniones se pueden comparar con otros estudios en el que se puede afirmar que se trata de una opinión generalizada en la sociedad española. Por ejemplo, MAPFRE (2009) publicó el informe "La sociedad ante el cambio climático. Conocimientos, valoraciones y comportamientos en la población española" en el que, respecto a las precipitaciones, en el ítem "cada vez llueve menos en España", el 40,8\% de los/las participantes respondió que "muy de acuerdo" y el 40,1\% "bastante de acuerdo". En el ítem "las tormentas y los temporales son ahora más frecuentes que antes" el 23,3\% contestó "muy de acuerdo" y el " $35,8 \%$ bastante de acuerdo". Y, para el caso de cómo puede afectar el cambio climático en el "incremento de las inundaciones", el 26,4\% contestó "muy de acuerdo" y el 34\% "bastante de acuerdo". En relación con el interés que muestra la población sobre los efectos y consecuencias del cambio climático se constató una pérdida de interés social sobre este tema debido a la crisis económica, situándose en el $5^{\circ}$ lugar del ranking de los problemas que preocupan a la población europea (MAPFRE, 2009). En la Comunidad Valenciana, en la ciudad de Alicante, MOROTE et al. (2019c) han mostrado, para el caso de los residentes de las urbanizaciones de chalés, que el cambio climático ocupa el último lugar (de 8 ítems) sobre los factores que inciden a la hora de reducir el consumo de agua en el hogar. Sin embargo, una encuesta a nivel mundial indica que el $67 \%$ de la población cree que el cambio climático es el principal problema al que se enfrenta el planeta (FUNDACIÓN AQUAE, 2019). 
Algunas de las observaciones de determinadas opiniones de diferentes encuestados/as (de los/as que han contestado que el centro escolar no se situaba en una zona de riesgo; ítem 11), ha sido su percepción " 0 " sobre el riesgo de inundación. Por ejemplo: "En mi pueblo no se sufren inundaciones, es un pueblo que está en una montaña", "En mi pueblo no hay inundaciones, es un pueblo muy llano", "Nunca me ha pasado a mí", "Mi colegio no estaba en una zona de inundación y además llueve poco" o "Mi colegio no se encuentra en una zona inundable, está en Valencia y no hay peligro". Cabe destacar que percepciones y experiencias personales que han tenido los/as participantes, pero ello no significa que su centro escolar o incluso alguna zona de su municipio no esté afectada por estos riesgos. Es decir, puede ser que estén ubicados en zonas de inundación con un periodo de retorno de 100 o 500 años. Respecto a los centros escolares, esto último no se puede constatar en este trabajo debido a la protección de datos pero sí con los términos municipales o con el propio núcleo urbano. En este sentido, algunas de estas opiniones reflejadas son de participantes donde el centro escolar se sitúa en Mislata (Huerta Oeste) y Almussafes (La Ribera Baixa). En ambos casos, según el PATRICOVA, los núcleos urbanos están afectados por el riesgo de inundación. Además, detrás de estas afirmaciones tan rotundas puede haber un desconocimiento importante del territorio, del clima mediterráneo y sobre la percepción de que el ser humano domina la naturaleza. Comentarios como "a mí nunca me va a pasar", "esto no sucede nunca" o "esto nunca lo he visto o vivido" no tiene por qué significar que una inundación no pueda suceder o que haya sucedido antes. U opiniones como "vivir en un llano". Si por algo se caracteriza la costa de la provincia de Valencia es por ser llana y ser una zona de marjal y de inundación. Éstas, constituyen unas de las principales opiniones de los/as entrevistados/as que aparecen en los medios de comunicación cuando sucede alguna catástrofe natural, que denota esa percepción de riesgo "0" y una escasa memoria climática. Por otra parte, que llueva poco es algo característico de muchas áreas de la región mediterránea española, pero también cabe destacar que es característico que estas precipitaciones (aunque escasas) sean de gran intensidad horaria. De ser este desconocimiento así, puede ser un aspecto negativo por los estereotipos que puedan transmitir los/as participantes en esta investigación, todo ello, teniendo en cuenta que serán futuros maestros/as de Primaria

Respecto al ámbito de la enseñanza, los problemas socio-ambientales (mejor que "ambientales" o "medioambientales"; cabe destacar que este último concepto es una reiteración de términos) constituyen un reto para la sociedad actual. Por ello, es un tema de sumo interés en el ámbito educativo en los diferentes niveles de formación. En el trabajo de MORALES et al. (2013:104) sobre temáticas socio-ambientales realizado a alumnos/as de magisterio de la Universidad de Valencia, se constató que estos presentaban un pensamiento deformado de la realidad social y ambiental del planeta, con "unas concepciones previas, en el alumnado, llenas de estereotipos y aprendizajes fragmentados y desvirtuados en detrimento del conocimiento integral y global". También, respecto a los problemas ambientales, en un reciente trabajo llevado a cabo por LÓPEZ et al. (2019), los autores plantean una investigación a modo de estudio de caso (Facultad de Ciencias de la Educación de la Universidad de Córdoba), desde la Didáctica de las Ciencias Sociales, en la formación del profesorado para analizar la representación social de los problemas ambientales desde un punto de vista género y el modo en el que se incluirían en las aulas de Educación Primaria por los/as futuros/as docentes. Los resultados obtenidos ponen de manifiesto que estos problemas son un tema relevante para los estudiantes; sin embargo, destaca un conocimiento conceptual bastante ambiguo marcado por la influencia de los medios de comunicación, así como una escasa capacidad para proponer secuencias didácticas que inciten a un cambio social necesario y una educación ambiental holística e integral. LÓPEZ et al. (2019) muestran como los principales problemas ambientales identificados por los futuros maestros de Primaria son la contaminación, el reciclaje y cuestiones relacionadas con el agua (su deterioro y la sequía). La idea con la que concluyen los autores es que los resultados obtenidos deben considerarse para adaptar las metodologías en la formación del profesorado para que les ayude a desarrollar en sus educandos una comprensión crítica y reflexiva de estos problemas. Por ello, conforme se vaya produciendo el crecimiento de los/as estudiantes, estos puedan interpretar, de manera razonada, la dependencia entre el ser humano y su entorno, y tener la capacidad para aportar soluciones a los problemas a partir de la puesta en práctica de sus conocimientos, valores y actitudes. 
En relación con el cambio climático, para el caso mexicano, por ejemplo, destaca el estudio realizado por GONZÁLEZ et al. (2014) sobre las representaciones sociales en estudiantes universitarios. Los resultados obtenidos por estos autores indican que la información científica transmitida por diversas fuentes, científicas y populares, no es suficientemente influyente entre los jóvenes para generar cambios de comportamiento orientados a frenar el cambio climático. Estos autores concluyen que se deberían tomar nuevas estrategias de comunicación y de educación ambiental dirigidas a generar conductas pro-ambientales en los/las discentes. En España, destacan algunos trabajos sobre las representaciones sociales y cambio climático como el realizado por ARTO (2009) en estudiantes de Primaria y Secundaria y sobre las concepciones de los estudiantes de formación básica y universitaria respecto al clima y el paisaje local (CAMPO et al., 2017). En relación con este último, estos autores reflejan que las idealizaciones que tienen los/as estudiantes respecto la explicación del clima, cambio climático y paisaje, son una sucesión continua de errores conceptuales y estereotipos que se arrastran por toda la formación básica y universitaria.

En Colombia, GIRALDO (2016) pone de manifiesto que hay mucho que hacer desde el campo de la educación para gestionar el riesgo debido a que este problema socio-ambiental cobra innumerables vidas debido a una alta vulnerabilidad de la población. Este autor explica que la Geografía de los riesgos cuenta con una larga tradición en el que los principios teóricos, conceptuales y metodológicos podrían ser parte de una propuesta didáctica donde se incorporen como contenidos a un proceso de enseñanza-aprendizaje. GIRALDO (2016) denuncia que la Geografía escolar aún se limita a la enseñanza tradicional de contenidos donde prima la localización y la memoria, pero, las nuevas tecnologías, tanto la Información Geográfica (TIG), como las de la Comunicación (TIC), brindan amplias posibilidades en el campo de la enseñanza de los saberes geográficos, proporcionando al docente herramientas para fomentar una didáctica que promueva un aprendizaje significativo. Al respecto, este autor propone la herramienta Google Earth en la enseñanza de la Geografía de los riesgos, indagando sobre la naturaleza del riesgo y los fundamentos teóricos y metodológicos de esta ciencia para formular preguntas espaciales que se podrían responder apoyados mediante esta herramienta.

Como se observa, resulta de interés de primer orden tratar en las aulas (en todos sus niveles) el fenómeno de los riesgos de inundación y el cambio climático, al igual que empleo de estrategias pedagógicas eficaces. MOROTE et al. (2019a) en su experiencia de una salida de campo sobre el riesgo de inundación han demostrado que el beneficio generado para el alumnado es inmediato, y a largo plazo, incontestable. A pesar de que esta experiencia se lleva a cabo en un postgrado, la idea de realizar estas salidas es adaptarlas según niveles educativos (Primaria, Secundaria, Bachillerato, Grado, e incluso en Infantil) ya que puede ser un recurso didáctico de notable interés para poder analizar in situ los espacios de riesgo. En este sentido, cualquier tipo de actividad formativa cala sobre la conciencia de las personas y les presta rápidamente unas capacidades de actuación ante situaciones de contingencia que antes no disponían por esa falta de percepción, que a la postre, se traduce en una minimización de la vulnerabilidad. MOROTE (2017) explica que urge la necesidad de aumentar el nivel del conocimiento sobre estos riesgos en las edades más tempranas ya que puede tener un doble efecto: 1) Tiende a mermar la vulnerabilidad global; y 2) Refuerza la capacidad de resiliencia o de recuperación después de una catástrofe de esa sociedad, de ahí la importancia de cualquier actividad instructiva. Este mismo autor, en la región valenciana expone el caso de estudio del Parque Inundable La Marjal (ciudad de Alicante) como un laboratorio para explicar el fenómeno de inundación al alumnado ya que permite ayudar a que estos puedan detectar, valorar e incluso realizar propuestas de corrección (actividades para todas las etapas escolares).

La labor de selección de los recursos y tipos de actividades a realizar en el aula, el compromiso por una pedagogía dinámica y experiencial, capaz de motivar a los niños y adolescentes y de hacer interesantes, atractivos y de más fácil comprensión los contenidos a impartir, dependen de cada enseñante (MARTÍNEZ et al., 2019). El aprendizaje basado en proyectos o la incorporación de temas novedosos (cambio climático, riesgos naturales) y formas de acercamiento a los elementos y procesos a estudiar pueden ser metodologías docentes válidas para aquellos maestros/as y profesores que quieren seguir innovando. Según MARTíNEZ et al. (2019) resulta de vital importancia la incorporación de contenidos novedosos como los riesgos asociados al clima o el 
propio cambio climático; si bien, debe escogerse correctamente el punto de vista en estos dos temas ya que no resulta favorable para el aprendizaje caer en un excesivo extremismo o catastrofismo. Por el contrario, se trata de temas que deben explicarse con realismo, es decir mostrando lo que realmente hay detrás de los riesgos y del cambio climático (agentes causales, efectos previstos, medidas de prevención y mitigación).

Una de las principales conclusiones comentadas en líneas anteriores es que la sociedad actual desconoce y no sabe interpretar el territorio que les rodea (errores conceptuales, estereotipos, percepción de riesgo 0, influencia de los medios de comunicación, etc.). Quizá el paso de una sociedad rural a una sociedad basada en los servicios y la pérdida de la identidad y apego al territorio han tenido algo que ver. Al respecto, NOGUÉ (2007: 137) indica que analizar un lugar es "hablar de identidad, porque la identidad no va sólo asociada a características tales como el sexo, la etnia o la lengua, sino también al espacio geográfico". Otros autores explican que los seres humanos tienden a identificarse con los lugares, desarrollando un sentido de pertenencia que se construye con la interrelación y el afecto que tiene con ese espacio geográfico concreto (CAVALCANTI, 2008), mientras que CALLAI (2009) indica ciertos elementos que constituyen la identidad de un lugar como los valores, las costumbres y las tradiciones que tienen como escenario de realización el espacio. ARAYA et al. (2018) explican que el pensamiento geográfico tiene un poder relevante para el conocimiento de los lugares y los territorios. Las personas que poseen este tipo de conocimiento tienen la capacidad de analizar integralmente las dimensiones espaciales y logran conceptualizar adecuadamente los diversos impactos que las acciones humanas tienen en el espacio geográfico. Comprender cómo se adquiere este tipo de pensamiento y determinar las claves para su desarrollo resulta interesante por su potencialidad epistemológica y didáctica.

En las Ciencias Sociales, y más concretamente en los temas de Geografía, esta ciencia puede ayudar a aumentar el conocimiento sobre el riesgo de inundación. La Geografía aporta en la educación la dimensión espacial del conocimiento, facilitando la comprensión de la información, de conceptos, procedimientos y actitudes referentes a la localización y distribución de diferentes hechos sobre el espacio (MOROTE, 2017; SOUTO, 2018). Para el caso de la Educación Primaria, cabe indicar que los contenidos geográficos que se tratan en el área de Ciencias Sociales permiten la adquisición de destrezas para analizar la ocupación del espacio por la sociedad y valorar críticamente el territorio resultante de esa transformación (SOUTO, 2007). MOROTE et al. (2017) explican que la enseñanza de Geografía debe orientarse hacia la formación de alumnos/as que posean las destrezas de comprender y analizar el territorio a partir de la localización y distribución de hechos relevantes y que sean capaces de obtener, interpretar, valorar y aplicar dicha información a los diferentes contextos de la vida diaria. Al respecto, BARRATT et al. (2000) explican que una educación geográfica que aborda las concepciones espontáneas sobre el medio cotidiano mejora la comprensión del entorno local y es capaz de modificar las aspiraciones y comportamientos de los estudiantes en beneficio de un desarrollo local sostenible.

DÍEZ et al. (2016) explican que las didácticas de las disciplinas escolares tienen la finalidad de preparar maestros/as para la enseñanza de unos contenidos específicos. Y, en palabras de TREPAT et al. (2008:134) "actualmente, en el campo de las Ciencias Sociales, desde una perspectiva de pensamiento crítico, el espacio se considera una variable básica de los hechos sociales y en constante relación dialéctica con la sociedad". En el proceso de aprender a interpretar y a intervenir en la práctica de la enseñanza de las Ciencias Sociales, en el caso particular de la Geografía, SANTISTEBAN (2008) propone la consideración de un modelo didáctico en forma de pirámide que refleja las relaciones entre profesorado, alumnado, unos contenidos concretos y un contexto. Por su parte, MORENO et al. (1995:47) ponen de manifiesto la importancia que han tenido las innovaciones en la metodología de la enseñanza de la Geografía, "tanto por lo que respecta a la búsqueda de una enseñanza más activa, como por la necesidad de adecuar el proceso de aprendizaje a la personalidad y evolución intelectual del alumno". Por tanto, la formación del maestro (actual y futuro) debería ser una prioridad para poder resolver el problema de la enseñanza de los riesgos y el conocimiento del funcionamiento y las características de un territorio.

\section{CONCLUSIONES}

Papeles de Geografía, 65 (2019), 67-88 
Con este trabajo se ha podido comprobar, a modo de caso de estudio (Universidad de Valencia), la percepción y experiencias que presentan los futuros maestros/as de Primaria sobre el riesgo de inundación y el cambio climático. Cabe indicar también las limitaciones de este tipo de estudio ya que se trata de "representaciones sociales". Por tanto, como reto futuro se deberá indagar no sólo sobre la experiencia de los/las participantes sino también conocer la procedencia de la información adquirida sobre el tema tratado. Esta cuestión es un tema interesante y fundamental. De este modo, se podrá observar cómo construyen su percepción para intervenir desde la Didáctica de la Geografía y las Ciencias Sociales. Ya MARTíN (2009) puso de manifiesto la importancia que tiene tratar estos temas debido a la falsedad y manipulación desde los medios de comunicación. Por tanto, resulta necesario formar correctamente a los futuros maestros/as y establecer una cultura del riesgo ya que el riesgo "0" no existe. Incrementar el conocimiento sobre esta temática en las cohortes más jóvenes debe ser una prioridad en la escuela. El currículo así lo establece y el geógrafo puede tener un importante papel en esta labor. Esto mismo ya fue denunciado por OLLERO (1997) ya que indicó hay que establecer una cultura del riesgo, una concienciación y sensibilización sobre los distintos elementos de peligrosidad y vulnerabilidad, vertiente de la educación ambiental que perfectamente puede ser desarrollada por geógrafos.

Con frecuencia los/as discentes no consiguen formar un pensamiento geográfico necesario para su participación activa en la sociedad. ARAYA et al. (2018) explican que actualmente existen diversas demandas para el trabajo docente en la enseñanza de la Geografía como son el proceso de formación de un pensamiento geográfico que permita a los estudiantes comprender el Mundo en el cual se encuentran insertos. Con ello, se podrá crear una sociedad más resiliente frente a los escenarios futuros de cambio climático. Al respecto, como ya se ha indicado en la parte introductoria, la EEA (2017) hace hincapié en la importancia de tener en cuenta el factor vulnerabilidad como elemento fundamental para abordar la adaptación al cambio climático. En los años ochenta, MCMANNUS (1989) ya puso de manifiesto la importancia de dedicarle una mayor atención al factor vulnerabilidad (donde se inserta la educación y formación de las cohortes más jóvenes) ya que, según este autor, el desconocimiento que existe sobre las normas de actuación más adecuadas, cuando éstos se producen, ocasiona el desarrollo de comportamientos y actitudes personales incorrectas que conducen a la toma de decisiones erróneas. Este concepto, el de vulnerabilidad, puede resultar esencial en la educación geográfica en la Educación Primaria y decisivo para lograr una sociedad más resiliente al cambio climático.

Desde la formación de los futuros maestros/as se debería hacer hincapié en tratar estos temas en las asignaturas de Ciencias Sociales y concienciar y contextualizar, en este caso, el área mediterránea ya que se trata de una región-riesgo (CALVO, 2001). La labor de selección de los recursos y tipos de actividades a realizar en el aula, el compromiso por una pedagogía dinámica y experiencial, capaz de motivar al alumnado y de hacer interesantes, atractivos y de más fácil comprensión los contenidos a impartir, dependerán de la formación y creatividad del docente. En este sentido, como indican MARTÍNEZ et al. (2019) cabe destacar el aprendizaje basado en proyectos o la incorporación de temas de interés (caso aquí analizado) y formas de acercamiento a los elementos y procesos a estudiar ya que pueden ser metodologías docentes válidas para los/as docentes que quieren seguir innovando. Por tanto, es de vital importancia concienciar a los/as futuros/as maestros/as sobre la incidencia del cambio climático y cómo puede influir local y globalmente, y dejar de lado las percepciones y tener también más en cuenta los trabajos científicos. Es algo que suele trabajarse en la escuela anglosajona como ya se ha explicado. Esto, resulta de mayor interés ya que son los/las docentes de Primaria el primer eslabón que tienen que tratar estos temas en el aula, especialmente a partir de $3^{\circ}$ (segundo ciclo de Primaria).

La labor docente requiere de responsabilidad, por lo que urge la necesidad de fortalecer cada día, todo aquello que se muestra con dificultad en los estudiantes, comprometiendo al educador a implementar metodologías que favorezcan continuamente la práctica docente (SOUTO, 2018) y lograr una educación geográfica y una ciudadanía crítica que sepa interpretar el medio en el que vive (SOUTO, 2007). Por ello, resulta de suma importancia despertar el interés al alumnado para que sepa interpretar críticamente el espacio que le rodea y valore y diferencie las afecciones que se producen en el medio, caso de las causas y consecuencias del cambio climático, desvinculando, 
de esta manera, los estereotipos que pueden adquirir principalmente desde los medios de comunicación y que los tomen como propios. La formación de la sociedad sobre cómo actuar ante un peligro natural o cómo ocupar un territorio puede ser determinante a la hora de minimizar los daños o que estos no sucedan.

Como conclusión, cabe ser conscientes de que se debe convivir con el riesgo. La Naturaleza ofrece bondades y dificultades y ésta debe ser respetada. Pero el riesgo es un aspecto condigno a la vida. Los escenarios futuros de cambio climático que pronostican diferentes informes, de cumplirse, obligan, por tanto, a lograr una sociedad más concienciada, formada y adaptada a estos escenarios donde la formación escolar debe ser un pilar fundamental.

\section{BIBLIOGRAFÍA}

AHMAD, S. y NUMAN, S.M. (2015): "Potentiality of disaster management education through open and distance learning system in bangladesh open university". Turkish Online Journal of Distance Education, vol. 16, nº 1 , p. 249-260.

ALAMINOS, A. y CASTEJÓN, J.L. (2006): Elaboración, análisis e interpretación de encuestas, cuestionarios y escalas de opinión. Vicerrectorado de Calidad y Armonización Europea. Instituto de las Ciencias de la Educación. Universidad de Alicante, Alicante, 119 pp.

ARAYA, F. y DE SOUZA, L. (2018): "Desarrollo del pensamiento geográfico: un desafío para la formación docente en Geografía". Revista de Geografía Norte Grande, n70, p. 51-69.

ARTO, M. (2009): "O cambio climático narrado por alumnos de educación secundaria: análise de metáforas e iconas". AmbientalMENTE sustentable. Vol. I, nº7, p. 115-125.

AYUNTAMIENTO DE VALENCIA (2019): Departamento de Estadística. Población del Área metropolitana de Valencia. en: http://www.valencia.es/ayuntamiento/catalogo.nsf/vDocumentosTituloAux/Estadistica\%20P or\%20territorio?opendocument\&lang=1\&nivel=3\&bdOrigen=ayuntamiento/estadistica.nsf \& idApoyo=58FB3C7A3D56E414C1257DD40057EB6C. [Consulta: 20 de Febrero de 2019].

BACH, J. (2008): "El riesgo de inundación: una propuesta de tratamiento". Revista Alambique, $\mathrm{n}^{\circ} 55$, p. 43-55.

BALLIN, B. (2007): "Climate change: a learning challenge". Primary Geography, n64, p. 3637.

BARRATT, R. y HACKING, E. (2000): "Changing my locality: conceptions of the future". Teaching Geography, no25 (1), p. 17-21.

BENEJAM, P. (1989): "Geografía y Educación”. Boletín de la Asociación de Geógrafos Españoles, nº, p. 1-9.

BENEJAM, P. (1997): La selección y secuenciación de los contenidos sociales. "Enseñar y aprender Ciencias Sociales, Geografía e Historia". En Benejam P. y Pagès, J. (Coord.). ICE Universidad de Barcelona/Horsori, Barcelona, pp. 71-95.

BENEJAM, P. (2011): "Conceptes bàsics sobre l'espai en l'enseyança i aprenentatge de la geografía". Perspectiva escolar, $\mathrm{n}^{\circ} 358$, p. 2-13.

BOON, H. (2014): "Teachers and the communication of climate change science: a critical partnership in Australia”. Procedia-Social and Behavioral Sciences, vol. 116, p. 1.006-1.010. https://doi.org/10.1016/j.sbspro.2014.01.336.

BRICELJ, M. (2013): "Kranjska stena - An example of good school practice”. Geografija v Soli, vol. 22, no $2-3$, p. 51-56.

CALIXTO, R. (2015): "Propuesta en educación ambiental para la enseñanza del cambio climático". Revista Electrónica Diálogos Educativos, vol. 15, p. 54-68.

CALLAI, H. (2009): El lugar y la enseñanza-aprendizaje de la geografía. "La espesura del lugar: Reflexiones sobre el espacio en el mundo educativo". En Garrido, M. (Ed.). Chile: Universidad Academia de Humanismo Cristiano, Chile, pp. 101-121.

CALVO, F. (2001): Sociedades y Territorios en Riesgo. Ediciones Serbal, Barcelona.

CAMPO, B. y MARTÍNEZ, M. (2017): Estudio del clima y paisaje de Ontinyent: vincular investigación educativa con innovación escolar. "Educaçao Geográfica na Modernidade Líquida, livro Atas do VIII Congresso Ibérico da Didática da Geografía". En A. Cámara, E. Sinde y M. Magro, pp. 349-361. 
CAVALCANTI, L. (2008): A geografia escolar e a cidade: Ensaio sobre o ensino de geografia para a vida urbana cotidiana. Campinas, Papirus.

CENTRE FOR RESEARCH ON THE EPIDEMIOLOGY OF DISASTERS (CRED). (2019): Economic Losses, Poverty \& Disasters (1998-2017). Disponible en: https://www.emdat.be/. [Consulta: 11 de Febrero de 2019].

CENTROS DE ESTUDIOS Y EXPERIMENTACIÓN DE OBRAS PÚBLICAS (CEDEX) (2017): Evaluación del impacto del cambio climático en los recursos hídricos y sequías en España. Centro de Estudios Hidrográficos. Ministerio de Fomento y Ministerio de Medio Ambiente, Madrid, $320 \mathrm{p}$.

CHANG, C. H. (2012): "The changing climate of teaching and learning school geography: the case of Singapore". International Research in Geographical and Environmental Education, $n^{\circ} 21(4)$, p. 283-295.

CHANG, C. H. y PASCUA, L. (2015): "The hole in the sky causes global warming': A case study of secondary school students' climate change alternative conceptions". Review of International Geographical Education Online (RIGEO), n5(3), p. 316-331.

CHANG, C. H. y PASCUA, L. (2016): "Singapore students' misconceptions of climate change". International Research in Geographical and Environmental Education, n²5(1), 84-96.

COHEN, L., MANION L. y MORRISON, K. (2002): Research Methods in Education. London, RoutledgeFalme.

DÍEZ, A. (2015): "Buscando riadas en los árboles: Dendrogeomorfología". Enseñanza de las ciencias de la tierra: Revista de la Asociación Española para la Enseñanza de las Ciencias de la Tierra, vol. 23, n²5, p. 272-285.

DÍEZ, A., LLORENTE, M., BALLESTEROS, J.A., y RUÍZ, V. (2009): "Riesgos por avenidas e inundaciones". Enseñanza de las Ciencias de la Tierra, vol. 17, n³, 254-263.

DÍEZ, J. y MIRALLES, P. (2016): "La Geografía en el tercer ciclo de Educación Primaria: estilos de aprendizaje y rendimiento académico". Boletín de la Asociación de Geógrafos Españoles, $\mathrm{n}^{\circ} 72$, p. 447-469.

DOMÈNECH, J. (2014): “Contextos de indagación y controversias socio-científicas para la enseñanza del cambio climático". Enseñanza de las Ciencias de la Tierra, vol. 22, n³, p. 287296.

EKLUND, S. (2018): Climate change education with a bright horizon?: Pedagogical reflections on teacher training for climate education that aims to empower students. Student thesis, Department of Math and Science Education, Faculty of Science,Stockholm University, p.24. URN: urn:nbn:se:su:diva-166036.

EUROPEAN ENVIRONMENT AGENCY (2017): Climate change, impacts and vulnerability in Europe 2016. An indicator-based report, Luxemburgo, 419 pp. Disponible en https://www.eea.europa.eu/publications/climate-change-impacts-and-vulnerability-2016 [Consulta: 29 de Julio de 2018].

EVANS, R.W., NEWMANN, F.M. y SAXE, D.W. (1996): Defining issues-centered education. "Handbook on Teaching Social Issues". En Evans R.W. y Saxe, D.W. (Eds.). National Council for the Social Studies, Washington, pp. 2-5.

FIEN, J. (1992): "Geografía, sociedad y vida cotidiana”. Documents d'anàlisi geogràfica, n²1, p. 73-90.

FREGENAL, M.A. (2009): "El delta del Ebro: Aula viva para la educación medioambiental y el análisis de los riesgos costeros". Enseñanza de las Ciencias de la Tierra, vol. 17, n³, p. 325337.

FUNDACIÓN AQUAE (2019): El cambio climático: crece la preocupación ciudadana mundial. Disponible en: https://www.fundacionaquae.org/actualidad/el-cambio-climatico-crece-lapreocupacion-ciudadanamundial/?fbclid=IwAR3xaZoD5edb8ZMYelXMgLXAGRUK8Z1BQ00FF7VxqgnlHIi9_sY u-GjJ0oo. [Consulta: 20 de Febrero de 2019].

GARCÍA, F. F. y DE ALBA, N. (2003): El patrimonio urbano como ámbito para tratamiento escolar de problemas sociales y ambientales. "El patrimonio y la didáctica de las ciencias sociales”. En Ballesteros, E., Fernández, C., Molina, J.A. y Moreno, P. (Eds.). Asociación 
Universitaria de Profesorado de Didáctica en las Ciencias Sociales (AUPDCS), Cuenca, pp. 81-89.

GARCÍA, F. F. y PORLÁN, R. (2000): "El proyecto IRES (Investigación y renovación escolar)”. Biblio 3W. Revista Bibliográfica de Geografía y Ciencias Sociales. Universidad de Barcelona, 205.

GARZÓN, G., ORTEGA, J.A., y GARROTE, J. (2009): "Las avenidas torrenciales en cauces efímeros: ramblas y abanicos aluviales". Enseñanza de las Ciencias de la Tierra, vol. 17, n³, 264-276.

GENERALITAT VALENCIANA (2019): Decreto 108/2014, de 4 de julio, del Consell, por el que se establece el currículo y desarrolla la ordenación general de la educación primaria en la Comunitat Valenciana. Disponible http://www.dogv.gva.es/datos/2014/07/07/pdf/2014_6347.pdf. [Consulta: 20 de Febrero de 2019].

GIRALDO, J.C. (2016): "Educación geografía, riesgos socioambientales y google earth". Revista DIM: Didáctica, Innovación y Multimedia, nº34, p. 1-19.

GONZÁLEZ, E. y MALDONADO, A. (2014): “¿Qué piensan, dicen y hacen los jóvenes universitarios sobre el cambio climático?: Un estudio de representaciones sociales". Educar em revista, $\mathrm{n}^{\circ} 3$, p. 35-55. Doi.org/10.1590/0104-4060.38106.

INTERGOVERNMENTAL PANEL ON CLIMATE CHANGE (IPCC) (2014): Climate Change 2013 and Climate Change 2014 (3 vols.). Disponible en: http://www.ipcc.ch/. [Consulta: 13 de Febrero de 2018].

INTERGOVERNMENTAL PANEL ON CLIMATE CHANGE (IPCC) (2018): Special Report Global warming of $1.5^{\circ} \mathrm{C}$ Disponible en: https://www.ipcc.ch/report/sr15/. [Consulta: 9 de noviembre de 2018].

IZQUIERDO, T., ABAD, M., QUINTERO-MORÁN, L. y RUÍZ, F. (2012): “Actividades didácticas como herramienta de aprendizaje de normas de actuación ante terremotos y tsunamis". Comunicaciones del XVII Simposio sobre Enseñanza de la Geología, Huelva 2012.

JONES, V. (2017): "Floods, deserts and disposable nappies". Primary Geography (Autumn), p. 28-29.

KOVACS, A., ŞTEFĂNIE, H., BOTEZAN, C., CRĂCIUN, I., y OZUNU, A. (2017): “Assesment of natural hazards in european countries with impact on young people". International Multidisciplinary Scientific GeoConference Surveying Geology and Mining Ecology Management, SGEM. 17th International Multidisciplinary Scientific Geoconference, SGEM 2017; Albena; Bulgaria; 29 Junio de 2017, vol. 17, nº52, p. 73-80.

LECHOWICZ, M. y NOWACKI, T. (2014): "School education as an element of natural disaster risk reduction". Prace i Studia Geograficzne, vol. 55, p. 85-95.

LOPEZ, J.A. y OLLER, M. (2019): "Los problemas medioambientales en la formación del profesorado de educación primaria". REIDICS: Revista de Investigación en Didáctica de las Ciencias Sociales, no 4, p. 93-109.

LUTZ, T. (2011): "Toward a new conceptual framework for teaching about flood risk in introductory geoscience courses". Journal of Geoscience Education, vol. 59, n ${ }^{\circ} 1$, p. 5-12.

MAPFRE (2009): La sociedad ante el cambio climático. Conocimientos, valoraciones y comportamientos en la población española. Disponible en: http://www.mapfre.com/ccm/content/documentos/fundacion/prev-ma/cursos/la-sociedadante-el-cambio-climatico.pdf. [Consulta: 20 de Febrero de 2019].

MARQUÉS, M. A. (2005): "Las inundaciones, caso práctico". Terceres Jornades del CRECIT: La didáctica de los riesgos naturales. Institut d'Estudis Andorrans. Andorra.

MARTÍN, J. (2009): "Diez verdades y diez mentiras en relación al cambio climático". Enseñanza de las Ciencias de la Tierra, vol. 17, n², p. 120-127.

MARTÍNEZ, L.C. y OLCINA, J. (2019): "La enseñanza escolar del tiempo atmosférico y del clima en España: currículo educativo y propuestas didácticas". Anales de Geografía de la Universidad Complutense, nº39 (1), p. 125.148.

MCEWEN, L., STOKES, A., CROWLEY, K. y ROBERTS, C. (2014): "Using role-play for expert science communication with professional stakeholders in flood risk management". Journal of Geography in Higher Education, vol. 38, n², p. 277-300. 
MCMANNUS, M. (1989): "El estrés postsísimico". Boletín de noticias de Medicina de Catástrofe, $\mathrm{n}^{\circ} 38$, p. 1-12.

MCWHIRTER, N. y SHEALY, T. (2018): "Case-based flipped classroom approach to teach sustainable infrastructure and decision-making”. International Journal of Construction Education and Research, p. 1-21.

MINISTERIO DE EDUCACIÓN, CULTURA Y DEPORTE (2019): Real Decreto 126/2014, de 28 de febrero, por el que se establece el currículo básico de la Educación Primaria. Disponible en: https://www.boe.es/buscar/pdf/2014/BOE-A-2014-2222-consolidado.pdf. [Consulta: 20 de Febrero de 2019].

MINISTERIO PARA LA TRANSICIÓN ECOLÓGICA (2019): Gestión de los riesgos de inundación. Disponible en: https://www.miteco.gob.es/es/agua/temas/gestion-de-los-riesgosde-inundacion/. [Consulta: 20 de Febrero de 2019].

MORALES, J.F. (1981): Las escalas de actitudes. "Metodología y Teoría de la Psicología”. En Morales J.F. (Ed.). UNED, Madrid.

MORALES, A.J., CAURÍN, C. y SOUTO, X.M. (2013): "Percepción del mundo: mapas mentales y problemas socioambientales". Didáctica Geográfica, nº 14 , p. 91-108

MORENO, A. y MARRÓN, M.J. (1995): Enseñar geografía de la teoría a la práctica. Madrid, Editorial Síntesis. $374 \mathrm{p}$.

MOROTE, A.F. (2017): "El Parque Inundable La Marjal de Alicante (España) como propuesta didáctica para la interpretación de los espacios de riesgo de inundación". Didáctica Geográfica, nº18, p. 211-230.

MOROTE, A.F. y MOLTÓ, E. (2017): "El Museo del Clima de Beniarrés (Alicante). Propuesta de un recurso didáctico para la enseñanza de la Climatología". Didáctica de las Ciencias Experimentales y Sociales, $\mathrm{n}^{\circ} 32$ (1), p. 109-131. DOI: 10.7203/DCES.32.9624.

MOROTE, A.F. y PÉREZ, A. (2019a): "La comprensión del riesgo de inundación a través del trabajo de campo: Una experiencia didáctica en San Vicente del Raspeig (Alicante)". Vegueta. Anuario de la Facultad de Geografía e Historia, n¹9, p. 609-631.

MOROTE, A.F., OLCINA, J. y HERNÁNDEZ, M. (2019b): "The Use of Non-Conventional Water Resources as a Means of Adaptation to Drought and Climate Change in Semi-Arid Regions: South-Eastern Spain". Water, 11, 93, p. 1-19. doi:10.3390/w11010093.

MOROTE, A.F., OLCINA, J., RICO, A.M. y HERNÁNDEZ, M. (2019c): "Water Management in Urban Sprawl Typologies in the City of Alicante (Southern Spain): New Trends and Perception after the Economic Crisis?". Urban Science, vol. 3, no 7 , p. 1-18. doi:10.3390/urbansci3010007.

NOGUÉ, J. (2007): “Paisaje, identidad y globalización”. Fabrikart, nº, p. 136-145.

OCHOA, A. S. (1996): Building a rationale for issue-centered education. "Handbook on Teaching Social Issues". En Evans, R. y Saxe, D. (Coords.). Washington: National Council for the Social Studies, pp. 6-12.

OLCINA, J. (2018): "Verdades y mentiras sobre el riesgo de inundaciones en el litoral mediterráneo: balance de medio siglo". Jornada sobre fenómenos meteorológicos extremos en el mediterráneo. 11 de diciembre de 2018. AEMET, Valencia.

OLLER, M. y VILLANUEVA, M. (2007): "Enseñar geografía en la educación secundaria: nuevos objetivos, nuevas competencias: un estudio de caso". Enseñanza de las ciencias sociales: revista de investigación, $\mathrm{n}^{\circ} 6$, p. 159-169.

OLLERO, A. (1997): "Crecidas e inundaciones como riesgo hidrológico. Un planteamiento didáctico".Lurr@lde, n²0, p.261-283.

OUARIACHI, T., OLVERA, M.D. y GUTIÉRREZ, J., (2017): "Evaluación de juegos online para la enseñanza y aprendizaje del cambio climático". Enseñanza de las ciencias: revista de investigación y experiencias didácticas, vol. $35, \mathrm{n}^{\circ} 1$, p. 193-214.

PAGÈS, J. y SANTISTEBAN, A. (2011): Les qüestionssocialment vives i l'ensenyament de les ciències socials. Barcelona: Servei de Publicacions de la Universitat Autònoma de Barcelona. Col. Documents, 97.

PÉREZ, M. (2011): "La geografía ante los desafíos del cambio climático: su impacto en la enseñanza”. Educación: una revista cubana que hace esencia de pensamiento, ${ }^{\circ} 133$, p. 5 11. 
PÉREZ, A., GIL, S. y OLCINA, J. (2015): "Housing bubbles and the increase of flood exposoure. Failures in flood risk management on the Spanish south-eastern coast (1975-2013)". Journal of Flood Risk Management, DOI: 10.1111/jfr3.12207.

PÉREZ, A., HERVÁS, F. N., y ROGEL, Y. Á. (2016): «Proposta metodològica per a l'avaluació de la vulnerabilitat social en poblacions afectades pel perill d'inundació: el cas d'Águilas (Múrcia, sud-est ibèric)». Documents d'Anàlisi Geogràfica, nº62(1), p. 133-159.

PLAN DE ACCIÓN TERRITORIAL SOBRE PREVENCIÓN DEL RIESGO DE INUNDACIÓN EN LA COMUNITAT VALENCIANA (PATRICOVA) (2015). Disponible en: http://www.habitatge.gva.es/es/web/planificacion-territorial-e infraestructuraverde/patricova-docs. [Consulta: 20 de Febrero de 2019].

RAMIRO, E. (1991): L'estudi vivencial: una eina de futur. Projecte d'investigació i innovació aprobado por la Conselleria de Cultura, Educació i Ciència de 4/06/1990 (DOGV: 24/08/1990). Finalizado en 1991 y dirigido por Xosé M. Souto.

RAMIRO, E. (1996a): "Per què s'inunda la Ribera", BALMA. Didàctica de les Ciències Socials, Geografia i Història, n³, p. 89-96.

RAMIRO, E. (1996b): Una comarca sobre alerta: La ribera del Xúquer", en III Jornadas de Didáctica de la Geografía, Madrid, España, pp. 329-336.

SANTIESTEBAN, A. (2008): La formación inicial del profesorado de Educación Primaria para enseñar ciencias sociales: futuro presente. "Didáctica de las Ciencias Sociales, Currículo Escolar y Formación del Profesorado". En ÁVILA, R.M., CRUZ, A. y DÍEZ, M.C. (Ed.). Jaén, Universidad de Jaén/Universidad Internacional de Andalucía/Asociación Universitaria del Profesorado de Didáctica de las Ciencias Sociales. Disponible en http://www. ujaen.es/investiga/hum167/XIXSimposioInternacional/download/DidacticaCienciasSocialesLibro.pdf.

SANTISTEBAN, A., GONZÁLEZ, N., PAGÈS, J. y OLLER, M. (2014): La introducción de temas controvertidos en el currículo de ciencias sociales: investigación e innovación en la práctica. "Historia e identidades culturales. V Simpósio Internacional de Didáctica de Las Ciencias Sociales en el Ámbito Iberoamericano”. En Prats, J., Barca, I. y López, R. (Eds.). Barcelona, España, pp. 310-322.

SPEAR, P. (2018): "Get in the picture about climate change". Primary Geography, n96, p. 2627.

SOUTO, X.M. (2005): "Educación ciudadana y didáctica de la geografia". Didáctica Geográfica, $\mathrm{n}^{\circ} 7$, p. $575-596$.

SOUTO, X.M. (2007): “Educación Geográfica y Ciudadanía”. Didáctica Geográfica, n9, p. 1132.

SOUTO, X. M. (2018): "La geografía escolar: deseos institucionales y vivencias de aula". Boletín de la Asociación de Geógrafos Españoles, $\mathrm{n}^{\circ} 79, \quad$ p. 1-31. http://dx.doi.org/10.21138/bage.2757.

TASHAKKORI, A. y TEDDLIE, C. (Eds.). (2003): Handbook of mixed methods in social and behavioral research. Tousand Oaks: Sage.

TREPAT, C.A. y COMES, P. (2008): El tiempo y el espacio en la didáctica de las ciencias sociales. Graó, Barcelona. 186 p.

UNIVERSIDAD DE VALENCIA (2019): Anuario estadístico. Disponible en:https://webges.uv.es/MS10/servlet/mstrWeb?evt=3010\&Server=MSTRATEGY\&Project $=$ RECULL\&. [Consulta: 21 de Febrero de 2019].

VALLS, M. L., BACH, J. y LINARES, R. (1990): "Los riesgos ambientales derivados de las avenidas. Su aplicación en la enseñanza". VI Simposio sobre Enseñanza de la Geología. Puerto de la Cruz, p. 330-344.

WISNER, B., BLAIKIE, P., CANNON, T. y Davis, I. (2004): At risk. Natural hazards, people's vulnerability, and disasters. Routledge, London and New York.

WOODHOUSE, S. (2007): "Exploring the future". Primary Geography, n64, p. 38-39.

YOUNG, R. (1993): Teoría crítica de la educación y discurso en el aula. Madrid: Paidós. 